\title{
Listado de síntomas breve (short checklist of symptoms) in Argentinean adults: psychometric study of its main clinical scales
}

\author{
Guadalupe de la Iglesia, ${ }^{1}$ Juliana Beatriz Stover, ${ }^{2}$ Mercedes Fernández Liporace, ${ }^{2}$ Alejandro Castro Solano ${ }^{1}$ \\ ${ }^{1}$ National Council of Scientific and Technological Investigations, University of Palermo, Buenos Aires; ${ }^{2}$ National Council of Scientific \\ and Technological Investigations, University of Buenos Aires, Buenos Aires, Argentina
}

\begin{abstract}
The main objective of this research was studying the psychometric properties of the Listado de sintomas breve (short checklist of symptoms; LSB-50) in a sample of 994 Argentinean adults (49.9\% females; 50.1\% males). Mean age was 40.66 years (standard deviation=17.01; Min=18; Max=89). This screening test has seven main clinical scales: hypersensitivity, obsessive-compulsive, anxiety, hostility, somatization, depression, and sleep disturbance. Pearson correlations indicated that all scales had positive and mostly moderate associations. The second order confirmatory factor analysis showed a good fit for a hierarchical model where all scales loaded in one major factor. Internal consistency by Cronbach's alpha was adequate. Females scored significantly higher than males in all scales except for the hostility scale, in which no differences were found. Although statistically significant associations with age were found in some scales, correlations were very weak. Obsessive-compulsive, sleep disturbance and depression scales had the highest scores, while anxiety presented the lowest score. Based on the psychometric evidence found, the scale seems to be suitable for the local population. Consequently, the availability of such measure may contribute to conduct epidemiological studies of psychopathology in Argentina. Moreover, the scale could be used for the assessment of psychotherapy progress and outcomes of clients, as well as for psychotherapy research. Notwithstanding, more evidence of validity and reliability should be sought.
\end{abstract}

Key words: Psychological symptoms; Mental health; Psychopathology; Adults; LSB-50.

\section{Introduction}

The prevalence of mental disorders widely varies across countries, with estimated percentages ranging

Correspondence: Guadalupe de la Iglesia, National Council of Scientific and Technological Investigations, University of Palermo, Av. Córdoba 3501, Buenos Aires, Argentina.

Tel: +54.11.4964.4600.

E-mail: gdelaiglesia@gmail.com

Acknowledgments: this work was supported by the National Council for Scientific and Technical Research (CONICET) under Grant PIP 11220110100504/2012-2014, Res. 2043/14.

Citation: de la Iglesia, G., Stover, J.B., Liporace, M.F., \& Castro Solano, A. (2016). Listado de síntomas breve (short checklist of symptoms) in Argentinean adults: psychometric study of its main clinical scales. Research in Psychotherapy: Psychopathology, Process and Outcome, 19(1):I-XII. doi: 10.4081/ripppo.2016.179

Received for publication: 12 June 2015

Revision received: 18 September 2015.

Accepted for publication: 17 December 2015.

This work is licensed under a Creative Commons Attribution NonCommercial 4.0 License (CC BY-NC 4.0).

(C) Copyright G. de la Iglesia et al., 2016

Licensee PAGEPress, Italy

Research in Psychotherapy:

Psychopathology, Process and Outcome 2016; 19:I-XII

doi:10.4081/ripppo.2016.179 from 4.3 to $26.4 \%$ (Demyttenaere et al., 2004; Polanczyk, Salum, Sugaya, Caye, \& Rohde, 2015; WHO International Consortium in Psychiatric Epidemiology, 2000). In Argentina, it is estimated that approximately $20 \%$ of Argentinean population suffer from some kind of mental disorder and Buenos Aires City and its greater metropolitan area present the highest prevalence (Ministry of Health, 2010). However, these statistics have been estimated based on other Latin-American countries, and thus, there is still a lack of accuracy and actualization of the information. National surveys of mental disorders in Argentina are out-dated (Casullo, 1983; Di Marco, 1981; Pagés Larraya, Casullo, \& Paso Viola, 1982). One of the main reasons is the absence of psychometric tests designed for screening psychopathology, with evidences of adequate validity and reliability. Estimating and analysing the prevalence of psychopathology in a population is one of the pivotal issues for public health (Kohn et al., 2005). Three main goals may be addressed by studying the presence of psychological symptoms in a population: i) determining the dimension of the problem; ii) exploring other psychological features that characterize individuals who suffer some type of psychopathology; and iii) identifying those individuals which are at risk of developing mental disorders in order to develop early interventions.

Thus, the availability of instruments specifically designed to accurately and briefly measure psychological symptoms results imperative. Researchers would benefit 
of these types of tests for describing the prevalence of psychopathology in the population, and for analysing the relationships among psychological symptoms and other variables such as socio-demographic characteristics and other psychological features. Moreover, these instruments would enable health providers to rapidly assess consultants and to refer those at risk of experiencing psychological discomfort to a thorough diagnosis and/or customized interventions. Screening tests meet this demand as they are specifically designed to assess a large number of people in a simple and rapid manner (Hernández Aguado et al., 2011; Lewis, Sheringham, Kalim, \& Crayford, 2008).

\section{Psychopathology screening tests and psychotherapy}

The availability of valid screening tests for assessing psychopathology can play an important role in the psychotherapy field. For example, if a screening measure is used before referring someone to psychotherapy, this could allow therapists: i) to save time assessing if treatment is needed and to work with accuracy with those clients; and ii) to know in advance the presumed diagnosis of the client, and thus, to evaluate if their expertise is appropriate for the client's needs or if a referral is required.

Additionally, since screening tests are easily responded and interpreted they may be useful for assessing psychotherapy progress. This has important clinical implications, as the scores obtained can function as additional empirical evidence of the client progress as well as the psychotherapy outcomes. According to Percevic, Lambert, and Kordy (2004), if clients receive immediate and continuous feedback from their therapists (a characteristic that screening tests would easily meet), their likelihood of treatment success will increase. When this hypothesis was tested, Shimokawa, Lambert, and Smart (2010) found that feedback interventions, such as this type of assessment, significantly enhanced treatment outcomes.

In the same line, Gennaro, Venuelo, Auletta, and Salvatore (2012) identified that one of the main topics in psychotherapy research is the study of self-report measures. Valid psychopathology screening tests are fundamental for psychotherapy research as they facilitate an initial screening of subjects in order to only select individuals who might meet the diagnostic criteria sought and, afterwards, applied in a smaller group of people the adequate diagnostic measures which demand more time and effort. For example, using screening measures in waiting rooms of primary care medical clinics, Roberge, Fournier, Menear, and Duhoux (2014) studied the access to psychotherapy of clients with anxiety disorders. This use of that instrument enable them to reduce the number of candidates from 14,833 to 3382 , which was a more manageable number of people to later and more accurately diagnose by Diagnostic and Statistical Manual of Mental Disorders criteria.

\section{Psychological symptoms: differences in prevalence and main sociodemographic associations}

Regardless of the wealth or culture of the population, when studying the prevalence of mental health disorders, anxiety and/or mood disorders - such as obsessive-compulsive, general anxiety, and depressive symptoms - arise as the most frequent mental ailments (Akihiro et al., 2015; Aillon et al., 2014; Caparrós Caparrós, Villar Hoz, Juan Ferrer, \& Viñas Poch, 2007; Casullo, 2004; Chadda, 2015; González de Rivera et al., 1999; Kessler et al., 2005; Klimas, Neary, McNicholas, Meagher, \& Cullen, 2014; Patel \& Stein, 2015; Sánchez \& Ledesma, 2009; The ESEMeD/MHEDEA 2000 Investigators et al., 2004; Stylianidis, Pantelidou, Chondros, Roelandt, \& Barbato, 2014). Therefore, they have been labelled as common mental disorders (Chadda, 2015; Goldberg \& Huxley, 1992).

Usually, studies indicate that males and females differ in the frequency they experience psychological symptoms. Women, compared to men, show more somatization, depression, anxiety, phobias and interpersonal sensitivity (Abuín \& de Rivera, 2014; Caparrós Caparrós et al., 2007; Carrasco Ortíz, Sánchez Moral, Ciccotelli, \& del Barrio, 2003; Casullo, 2004; Chadda, 2015; Cwikel, Zilber, Feinson, \& Lerner, 2008; González de Rivera et al., 1999; Houghton et al., 2012; King et al., 2008; Martínez Azumendi, Fernández Gómez, \& Beitía Fernández, 2001; Ruipérez, Ibáñez, Lorente, Moro, \& Ortet, 2001; Sánchez \& Ledesma, 2009; The ESEMeD/MHEDEA 2000 Investigators et al., 2004; Urbán et al., 2014; WHO International Consortium in Psychiatric Epidemiology, 2000). Men, on the other hand, present more psychoticism and hostility than women (Aillon et al., 2014; Gempp Fuentealba \& Avendaño Bravo, 2008; Urbán et al., 2014). However, there are also some reports of no differences by sex in paranoid ideation, interpersonal hostility, and psychoticism (Casullo, 2004; Gempp Fuentealba \& Avendaño Bravo, 2008; González de Rivera et al., 1999; Martínez Azumendi et al., 2001; Sánchez \& Ledesma, 2009).

When analysing the association with age, several studies found that as people get older symptoms of somatization and depression increase while hostility and hypersensitivity decline (Abuín \& de Rivera, 2014; González de Rivera et al., 1999). However, some research has found no relationship between age and none of the symptoms commonly assessed by screening measures (Carrasco Ortíz et al., 2003; Casullo \& Castro Solano, 1999) nor between age and anxiety or obsessive-compulsive (González de Rivera et al., 1999).

\section{Psychopathology assessment: self-report and the sample issue}

One of the main challenges of psychological assessment is that psychological symptoms are subjective expressions. Thus, the quality of the information obtained by self-reports is often disputed. A common characteristic 
of screening measures is that they are usually self-reports. This is the preferred method as they are economic in terms of time and money (Holi, 2003). However, a recurrent critic of self-reports is their alleged weakness to accurately represent individuals' discomfort (Corcoran \& Fischer, 2000). Self-report measures are commonly criticized for entailing social desirability responding and recall errors (Chan, 2009). Nonetheless, it has been remarked that this type of instruments facilitates a more freely and sincere communication of the symptoms experienced (Corcoran \& Fischer, 2000; de Rivera \& Abuín, 2012). Besides this, research has shown that their scores and clinical diagnosis converge significantly (Morlan \& Tan, 1998; Sturm et al., 2010). In this sense, Holi (2003) states that self-report measures are designed to control for the possible influence of the interviewer and to rapidly gather clinical information. Screening tests provide the first approximation to individuals' psychopathology, detecting those subjects at risk, in order to accurately diagnose and treat them.

When the assessment of psychological features in a specific culture will be conducted by psychological test, the psychometric properties of that instrument should be first studied in that particular population. Because psychological symptoms are thought to be highly dependent on the population under study (Casullo, Cruz, González, \& Maganto, 2003; De Las Cuevas et al., 1991), the particularities of the sample used to conduct those required psychometric studies is highly important and this issue has been the object of academic debate.

Some scholars argue that if the instrument aims at identifying subjects under psychological distress, the sample should be representative of the clinical population in order to entail more variability. In a sample of general population, positive asymmetry would be the most likely scenario (e.g. de Rivera \& Abuín, 2012; Hoffmann \& Overall, 1978). However, other academics suggest that the use of clinical populations also present biases. Since they score higher on psychological distress than the general population, results should not be extrapolated to nonclinical groups (Carrasco Ortíz et al., 2003; De Las Cuevas, 1991; Sánchez \& Ledesma, 2009). Although, studies with mixed samples constitute an ideal strategy (Bados, Balaguer, \& Coronas, 2005), most researchers use data from general population due to its accessibility (e.g. Daoud \& Abojedi, 2010; Ruipérez et al., 2001).

It should be consider that general population do not necessarily mean normal population. Thus, as the main objective of screening test of psychopathology is to detect individuals at risk from the general population, the idea of using a sample of those characteristics presents as a judicious strategy (Eaton, Neufeld, Chen, \& Cai, 2000).

\section{Screening measures: reliability and validity}

The revised version of the symptom checklist (SCL90-R; Derogatis, 1983) is the most widely employed screening instrument to assess psychological symptoms. It has been adapted in many populations, such as Argentina (Casullo, 1998; Sanchez \& Ledesma, 2009), Spain (De Las Cuevas et al., 1991), China (Zhang \& Zhang, 2013), and Chile (Gempp Fuentealba \& Avendaño Bravo, 2008), among other countries. As the SCL-90-R resulted long for screening purposes, a shorter version the Brief Symptom Inventory (BSI) - was developed (Derogatis, 1975; Derogatis \& Spencer, 1982). The BSI was adapted to be used in countries such as Israel (Canetti, Shalev, \& De-Nour, 1994), Spain (Ruipérez et al., 2001), Jordan (Daoud \& Abojedi, 2010), Turkey (Sahin \& Durak, 1994), Russia (Ritsner, Rabinowitz, \& Slyuzberg, 1995), Italy (De Leo, Frisonai, Rozzini, \& Trabucchi, 1993), the Philippines (Aoian, Patsdaughter, Levin, \& Gianan, 1995), and Korea (Noh, Avison, \& Kaspar, 1992). In general, psychometric studies report adequate reliability but many difficulties to obtain evidences of validity. Actually, several adaptations only constitute mere translations of the original and lack the required psychometric studies.

An even shorter version of the scale, the BSI-18 was developed (Derogatis, 2001) and adapted in countries such as Ireland (Houghton et al., 2012), Mexico (Torres, Miller \& Moore, 2013), and China (Liu, Chen, Cao, \& Jiao, 2013). Nevertheless, this version also presented difficulties when attempting to establish validity evidence. Prinz et al. (2013) compared the SCL-90-R and its shorter versions and concluded that the latter ones were psychometrically more adequate and, therefore, recommended to be used as screening instruments.

Generally, the difficulty found when assessing the validity of these instruments relies on determining their factorial structure. Items tend to show complex loadings and the factorial structures usually differ in the amount of dimensions isolated (Cyr, McKenna-Foley, \& Peacock, 1985; Martínez Azumendi et al., 2001). As psychometric theory postulates, in order to generate valid measurements, a scale must be reasonably reliable. Still, a reliable scale is not necessarily valid (Kerlinger \& Lee, 2000). Consequently, although desired, reliable results do not guarantee valid measures and, therefore, evidence of validity are imperative.

Screening measures of psychopathology, such as the ones aforementioned, have mostly had good internal consistency estimated by Cronbach's alpha (e.g. Abuín \& de Rivera, 2014; Caparrós Caparrós et al., 2007; Carrasco Ortíz et al., 2003; Casullo \& Castro Solano, 1999; Ruipérez et al., 2001). Conversely, construct validity studies by factor analysis display a considerable variety of results that indicate factor structures varying from one to even eight dimensions (e.g. Abuín \& de Rivera, 2014; Daoud \& Abojedi, 2010; De Las Cuevas et al., 1991; Hoffmann \& Overall, 1978; Urbán et al., 2014). Researchers have found difficulties replicating the nine-dimensional structure of the SCL-90-R by confirmatory factor analyses (Hardt, Gerbershagen, \& Franke, 2000; 
Rauter, Leonard, \& Swett, 1996; Schmitz et al., 2000; Vassend \& Skrondal, 1999). According to de Rivera and Abuín (2012) the persistent factorial inconsistency might be explained by clinical comorbidity.

Nevertheless, a higher-order unique factor that measures general psychiatric distress is frequently found (Benishek, Hayes, Bieschke, \& Stoffelmayr, 1998; Bonynge, 1993; Boulet \& Boss, 1991; Cyr et al., 1985; Daoud \& Abojedi, 2010; Grande, 2014; Loutsiou-Ladd, Panayiotou \& Kokkinos, 2008; Martínez Azumendi et al., 2001; Piersma, Boes, \& Reaume, 1994; Prunas, Sarno, Preti, Madeddu \& Perugini, 2012; Torres et al., 2013; Zach, Toneatto \& Streiner, 1998). Additionally, strong positive correlations among symptoms scores reflect great convergence between scales (Abuín \& de Rivera, 2014; Casullo \& Castro Solano, 1999; Caparrós Caparrós et al., 2007; Chapman, Petrie, \& Vines, 2012).

\section{Listado de síntomas breve (short checklist of symptoms)}

De Rivera and Abuín (2012) examined the SCL-90-R and developed the Listado de sintomas breve (LSB-50)short checklist of symptoms - in an attempt to produce a short, reliable and, most importantly, valid measure of psychopathology. The exclusion of both Paranoid Ideation and Psychoticism scales was among the main changes introduced. In this respect, Eaton et al. (2000) remarked that self-report measures are not suitable for assessing psychotic disorders. Moreover, de Rivera and Abuín (2012) stated that these aspects should not be included in self-report tests, as they comprise items with unclear content. These items might be confusing for respondents and cover symptoms that are easily detectable by clinical interviews. In fact, a study conducted in Italy found that Paranoid Ideation and Psychoticism dimensions did not emerge as differentiated factors in the analyses and showed an erratic psychometric behaviour (Prunas et al., 2012). Additionally, some language adjustments were done in order to more accurately reproduce people expressions. For instance, Trouble falling asleep, was replaced by I find it difficult to fall asleep. Furthermore, these authors added the assessment of an essential aspect of psychological discomfort: sleep disturbance.

Until now, psychometric studies of the LSB-50 (Abuín \& de Rivera, 2014; de Rivera \& Abuín, 2012) include correlations with other psychometric measures of self-perception and interpersonal relationships; analysis of internal consistency by Cronbach's alphas; an exploratory factor analysis that indicated a six-components structure with hypersensitivity and obsessive-compulsive items loading in the same factor and discriminant analysis. Also, a study conducted in Colombia (Rojas Gualdrón, 2012) analysed a second-order model that showed a good fit. Notwithstanding, the first order dimensions did not replicate those suggested by de Rivera and Abuín (2012).

As the LSB-50 was designed to overcome the difficulties found in the SCL-90-R, studies of validity are needed and research should examine if the LSB-50 actually constitutes an improvement of the above-mentioned screening measures of psychopathology. Consequently, the main goal of this study is to describe the psychometric characteristics of the LSB-50 in a sample of Argentinean adults, in order to provide mental health professionals and researchers with an adequate instrument. It was hypothesised that: i) there would be significant associations among the main clinical scales; ii) a second-order model where the seven clinical scales load in a major measure of general psychiatric distress would have a good fit; iii) the scales would have good internal consistency; iv) there would be significant sex differences in the scales; v) an association between age and the presence of psychopathology would be found; and vi) obsessive-compulsive and depressive symptoms would arise as the most frequent manifestations.

\section{Methods}

\section{Participants}

Participants were 994 Argentinean adults of ages between 18 and 89 years old (mean $=40.66$; standard deviation=17.01). They were proportionally distributed by sex (49.9\% females; $50.1 \%$ males). Half of the sample $(51.1 \%)$ was married or in a relationship, $36.8 \%$ was single, $8.3 \%$ was divorced/separated, and $3.8 \%$ was widow(/er)s. Regarding education, most of them (49.0\%) completed high school, $42.8 \%$ had a college diploma, $8 \%$ just achieved elementary education, and the remaining, $0.2 \%$ reported no formal education.

\section{Materials and procedure}

The LSB-50 (de Rivera \& Abuín, 2012) is composed by 50 items that refer to different psychological symptoms. Participants are instructed to indicate to which degree each of the items has bothered them in the last few weeks including the present day. Responses are valued in a 5 -point Likert scale, ranging from $0=$ nothing to $4=a$ lot. Seven clinical scales are assessed: i) hypersensitivity (seven items), that refers to intra and interpersonal sensitivity (e.g. I think other people watch me or talk about $m e$ ); ii) obsessive-compulsive (seven items), which attempts to cover the presence of doubts, rituals, and compulsions (e.g. I have to do things very slowly in order to be sure that I am doing them right); iii) anxiety (nine items), that enquires about symptoms of panic, general anxiety disorder and phobic disorders (e.g. I feel scared in the street or in open spaces); iv) hostility (six items), which asks about behaviours of rage, anger and resentment (e.g. I want to break or destroy something); v) somatization (eight items), that assesses somatic symptoms that have basis on psychological or medical problems (e.g. My heart throbs or beats really fast); vi) depression (ten items), which examines lack of energy, guilt, sadness, and 
hopelessness (e.g. I feel sad); and vii) sleep disturbance (three items), that inquires possible sleeping difficulties from a wellbeing perspective (e.g. I wake up at dawn). Also, two more clinical scales may be evaluated: psychoreactivity, which includes obsessive-compulsive and hypersensitivity elements; and sleep disturbance extended, that covers the measurement of anxiety and depression symptoms. Additionally, a total of four comprehensive indexes of severity can be addressed: i) global severity index; ii) number of symptoms; iii) intensity of symptoms index; and iv) risk of psychopathology index. In order to detect distortions in answers (showing less or more psychological discomfort) there are two supplementary scales: magnification and minimization.

A convenience sample with volunteer participants was obtained in 2013 in Buenos Aires City. It was coordinated by two trained psychologists who work at the University of Buenos Aires. Participants met the following inclusion criteria: being Argentinean and older than 18 years. Adults who were under psychiatric treatment were not included in the assessment. Before providing an informed consent, participants were informed about the objective of the research and the possibility to refuse or to interrupt their participation at any time. No incentives were given neither to participants nor to data collectors.

\section{Results}

Firstly, Pearson correlations among all scales were obtained (Table 1). All the associations were positive and statistically significant $(\mathrm{P}<.01)$. The strongest relationships found were between Depression and Hypersensitivity $(r=.77)$, Depression and Anxiety $(r=.72)$, and, Hypersensitivity and Anxiety ( $r=.68)$. The weakest correlations observed were between Sleep disturbance and Hostility $(r=.30)$.

Then, univariate statistics were calculated for each element (Table 2). Most means have values around 0.5/1. Skewness and kurtosis values indicate lack of univariate normal distribution for most items. Additionally, a nor- malized estimate of Mardia's coefficient of 258.44 indicated a non-normally multivariate distribution.

A second order confirmatory factor analysis was performed to analyse the adequacy of a hierarchical model that postulated that the seven clinical scales loaded in one major dimension of general distress. The estimation method chosen was robust maximum likelihood. Also, the matrix used was the polychoric correlation matrix, which is more appropriate when variables are ordinal (as in the case of the LSB-50) and when there is evidence of high values of skewness and kurtosis (Freiberg Hoffmann, Stover, de la Iglesia, \& Fernández Liporace, 2013; Muthen \& Kaplan, 1985). The statistical package EQS 6.2 was used for this analysis.

Different indexes obtained by the robust method were examined to value model fit: Satorra-Bentler Scaled ChiSquare (S-B), Normed-of-Fit Index (NFI), Incremental Fit Index (IFI), Comparative Fit Index (CFI) and Root Mean Square Error of Approximation (RMSEA). All indexes showed an excellent fit of a hierarchical model of seven first-order factors and one second order factor, S$\mathrm{B}=2723.43(\mathrm{P}<.001) \quad \mathrm{NFI}=.967 ; \mathrm{IFI}=.981 ; \mathrm{CFI}=.981 ;$ RMSEA $=.037$ (confidence interval $90 \%=.035-.038$ ).

Additionally, all regression paths (factorial weights) were statistically significant. None of them showed a negative sign nor exceeded the value of 1 . First order and second order factorial weights were higher than the minimum accepted (Kline, 2011) as seen in Figure 1. Only item 6 had a slightly lower weight than expected (item $6=.34$ ).

Cronbach's alpha coefficients were calculated in order to study scales' internal consistency. All of them showed excellent internal consistence. Values ranged from .72 to .83 (Table 3). Sleep disturbance, Anxiety and Depression displayed the highest levels of internal consistency.

Descriptive statistics were calculated for each scale. Independent sample $t$-tests were used to estimate differences by sex in the main clinical scales and effect sizes were calculated by Cohen's $d$ (Table 4). Differences were found in all the scales with the exception of Hostility $(\mathrm{P}=.26)$. In all those scales, females scored significantly higher than men, with moderate effect sizes.

Table 1. Pearson correlations among the main clinical scales.

\begin{tabular}{|c|c|c|c|c|c|c|c|}
\hline & Hypersensitivity & Obsessive-compulsive & Anxiety & Hostility & Somatization & Depression & Sleep disturbance \\
\hline Hypersensitivity & 1 & & & & & & \\
\hline Obsessive-compulsive & $.65^{* *}$ & 1 & & & & & \\
\hline Anxiety & $.68^{* *}$ & $.59^{* *}$ & 1 & & & & \\
\hline Hostility & $.49^{* *}$ & $.45^{* *}$ & $.44^{* *}$ & 1 & & & \\
\hline Somatization & $.53^{* *}$ & $.47^{* *}$ & $.60^{* *}$ & $.39^{* *}$ & 1 & & \\
\hline Depression & $.77^{* *}$ & $.61^{* *}$ & $.72^{* *}$ & $.50^{* *}$ & $.63^{* *}$ & 1 & \\
\hline Sleep disturbance & $.34^{* *}$ & $.33^{* *}$ & $.35^{* *}$ & $.30^{* *}$ & $.44^{* *}$ & $.40^{* *}$ & 1 \\
\hline
\end{tabular}

${ }^{* *} \mathrm{P}<.01$. 
Next, associations between age and each scale were examined. Pearson correlations stated that Hypersensitivity $(r=-.09, \mathrm{P}=.004)$, Obsessive-compulsive $(r=-.07$, $\mathrm{P}=.019)$ and Hostility $(r=-.13, \mathrm{P}<.001)$ had negative and low associations with age. Additionally, the relationship between age and Sleep disturbance was positive but low $(r=.11, \mathrm{P}<.001)$. No associations were found for Anxiety, Somatization and Depression (Table 5).

Finally, a within-subjects ANOVA was conducted to contrast the scores of the main clinical scales. The model was statistically significant, Wilks's $\lambda=.44$; $F(6,988)=213.43 ; \mathrm{P}<.001 ; \eta^{2}=.56$. Bonferroni's pairwise comparison indicated that differences were statistically significant in almost every pair $(\mathrm{P}<.05)$. However, no differences were found between Hypersensitivity and Somatization $(\mathrm{P}=.556)$, between Hostility and Somatization $(\mathrm{P}=1)$, nor between Hostility and Depression $(\mathrm{P}=1)$, or between Somatization and Depression $(\mathrm{P}=.414)$. The analy- sis of each scale' means revealed that in descent order, scores were as follows: obsessive-compulsive, sleep disturbance, depression, hostility, somatization, hypersensitivity, and anxiety (see Table 4 for means and standard deviations).

\section{Discussion}

This research aimed at studying some psychometric properties of the LSB-50 (de Rivera \& Abuín, 2012) in a sample of Argentinean adults. The analyses focused on the seven main clinical scales and included the study of their relationships, testing a second order model, internal consistency, sex and age differences, and differences in the levels of symptomatology of each scale.

Pearson correlations indicated that the associations among clinical scales were all positive and mostly strong. The results were as expected and reproduced findings

Table 2. Univariate statistics for the items.

\begin{tabular}{|c|c|c|c|c|c|c|c|}
\hline Item & Mean (SD) & Skewness & Kurtosis & Item & Mean (SD) & Skewness & Kurtosis \\
\hline 1 & $0.96(1.03)$ & 0.72 & -0.44 & 26 & $0.45(0.84)$ & 2.15 & 4.58 \\
\hline 2 & $0.93(0.99)$ & 0.95 & 0.33 & 27 & $0.88(1.17)$ & 1.17 & 0.23 \\
\hline 3 & $0.60(0.95)$ & 1.67 & 2.17 & 28 & $0.84(1.04)$ & 1.16 & 0.56 \\
\hline 4 & $1.04(1.08)$ & 0.84 & -0.11 & 29 & $0.35(0.75)$ & 2.37 & 5.33 \\
\hline 5 & $0.36(0.83)$ & 2.66 & 6.88 & 30 & $0.90(1.07)$ & 1.10 & 0.46 \\
\hline 6 & $1.87(1.39)$ & 0.03 & -1.27 & 31 & $0.51(0.83)$ & 1.76 & 2.84 \\
\hline 7 & $1.21(1.17)$ & 0.71 & -0.44 & 32 & $0.35(0.73)$ & 2.40 & 5.93 \\
\hline 8 & $1.34(1.18)$ & 0.54 & -0.67 & 33 & $0.66(1.05)$ & 1.58 & 1.62 \\
\hline 9 & $1.21(1.11)$ & 0.68 & -0.35 & 34 & $0.43(0.84)$ & 2.26 & 4.95 \\
\hline 10 & $0.48(0.86)$ & 1.92 & 3.31 & 35 & $0.45(0.79)$ & 2.03 & 4.09 \\
\hline 11 & $0.92(1.11)$ & 1.15 & 0.48 & 36 & $0.84(1.03)$ & 1.13 & 0.53 \\
\hline 12 & $0.98(1.10)$ & 1.03 & 0.26 & 37 & $0.55(0.93)$ & 1.83 & 2.95 \\
\hline 13 & $1.07(1.23)$ & 0.93 & -0.27 & 38 & $0.47(0.85)$ & 2.01 & 3.77 \\
\hline 14 & $0.96(1.23)$ & 1.07 & -0.07 & 39 & $0.97(1.18)$ & 1.05 & 0.02 \\
\hline 15 & $1.23(1.21)$ & 0.66 & -0.63 & 40 & $0.46(0.84)$ & 2.13 & 4.53 \\
\hline 16 & $0.75(0.99)$ & 1.33 & 1.15 & 41 & $0.42(0.82)$ & 2.17 & 4.49 \\
\hline 17 & $0.12(0.47)$ & 4.73 & 25.46 & 42 & $0.40(0.78)$ & 2.21 & 4.90 \\
\hline 18 & $0.33(0.75)$ & 2.75 & 8.03 & 43 & $0.91(1.12)$ & 1.16 & 0.52 \\
\hline 19 & $0.70(1.01)$ & 1.37 & 0.97 & 44 & $1.08(1.07)$ & 0.80 & -0.13 \\
\hline 20 & $0.54(0.90)$ & 1.82 & 2.87 & 45 & $0.36(0.79)$ & 2.58 & 6.75 \\
\hline 21 & $0.33(0.75)$ & 2.74 & 7.88 & 46 & $0.34(0.76)$ & 2.69 & 7.48 \\
\hline 22 & $0.59(1.01)$ & 1.83 & 2.68 & 47 & $0.33(0.74)$ & 2.63 & 6.69 \\
\hline 23 & $0.40(0.80)$ & 2.22 & 4.83 & 48 & $0.30(0.72)$ & 2.78 & 8.08 \\
\hline 24 & $0.78(1.02)$ & 1.37 & 1.15 & 49 & $1.25(1.78)$ & 0.65 & -0.51 \\
\hline 25 & $0.23(0.63)$ & 3.26 & 11.54 & 50 & $0.55(0.90)$ & 1.87 & 3.27 \\
\hline
\end{tabular}

$\mathrm{SD}$, standard deviation. 
from previous research (Abuín \& de Rivera, 2014; Casullo \& Castro Solano, 1999; Caparrós Caparrós et al., 2007; Chapman et al., 2012). Moreover, these results highlight the need to reconsider the use of a general instrument to measure mental discomfort based on the high comorbidity of the assessed symptoms. Effectively, the second order confirmatory factor analysis indicated the adequacy of a model in which the seven main clinical scales loaded in one single dimension of psychological discomfort. An excellent overall fit of the structure was indicated by fit indexes. In detail, regression paths of all items and first order factors were all significant and displayed the expected loadings. This higher unique dimension of general psychiatric distress replicates previous findings (e.g. Benishek et al., 1998; Bonynge, 1993; Boulet \& Boss, 1991; Cyr et al., 1985; Daoud \& Abojedi, 2010; Grande, 2014; Loutsiou-Ladd et al., 2008; Martínez Azumendi et al., 2001; Piersma et al., 1994; Prunas et al., 2012; Torres et al., 2013; Zach et al., 1998). Compared to de Rivera and Abuín's (2012) factor analysis who had provided evidence for the use of subscales scores, here this results justify not only the use of subscales scores but also the use of a total score disregarding age or sex of the respondant.

Furthermore, Cronbach's alphas indicated high internal consistency for all clinical scales. These findings complements the evidence of construct validity obtained in the prior analysis and are in line with the evidence of reliability consistently obtained with the different versions of the SCL-90-R (Abuín \& de Rivera, 2014; Carrasco Ortíz et al., 2003; Casullo \& Castro Solano, 1999; Caparrós Caparrós et al., 2007; Ruipérez et al., 2001).

Sex differences were found in all clinical scales except for Hostility. In all cases women scored higher than men. This partially replicates results from other studies since women tend to inform more somatization, depression, anxiety, phobias and interpersonal sensitivity (Abuín \& de Rivera, 2014; Caparrós Caparrós et al., 2007; Carrasco Ortíz et al., 2003; Casullo, 2004; González de Rivera et al., 1999; Houghton et al., 2012; Martínez Azu- mendi et al., 2001; Ruipérez et al., 2001; Sánchez \& Ledesma, 2009; Urbán et al., 2014). The absence of differences in Hostility contradicts some precedents of men scoring significantly higher than women (Gempp Fuentealba \& Avendaño Bravo, 2008; Urbán et al., 2014), but reproduce other studies where no differences were found (Casullo, 2004; González de Rivera et al., 1999; Sánchez \& Ledesma, 2009). Caparrós Caparrós et al. (2007) hypothesised different explanations for this sex difference: biology reasons, stating that organic changes are responsible for the presence of more symptoms in women; gender differences in the expression of emotions and socialization regarding the assumed role for women and men in the society. The World Health Organization (WHO, 2015) clearly states that gender differences in mental disorders are not to be taken lightly and more research is needed. According to the WHO (2015), the exposure to gender-based violence, disadvantaged socioeconomic status, and social inequality together with a relentless responsibility for taking care of others are some of the underlying reasons for gender differences in psychopathology. These factors are much more tangible than those propose by authors like Caparrós Caparrós et al. (2007), and can trigger very specific interventions to prevent psychopathology in women.

Regarding the associations between psychopathology

Table 3. Cronbach's $\alpha$ for the main clinical scales.

\begin{tabular}{lc}
\hline & Cronbach's $\boldsymbol{\alpha}$ \\
\hline Hypersensitivity & .79 \\
\hline Obsessive-compulsive & .72 \\
\hline Anxiety & .83 \\
\hline Hostility & .81 \\
\hline Somatization & .77 \\
\hline Depression & .82 \\
\hline Sleep disturbance & .83 \\
\hline
\end{tabular}

Table 4. Descriptive statistics and sex differences in the main clinical scales.

\begin{tabular}{lcccccccc}
\hline & Minimum & $\begin{array}{c}\text { Main sample } \\
\text { Maximum }\end{array}$ & Mean (SD) & $\begin{array}{c}\text { Females } \\
\text { Mean (SD) }\end{array}$ & $\begin{array}{c}\text { Males } \\
\text { Mean (SD) }\end{array}$ & $\boldsymbol{t}$ & $\begin{array}{c}\boldsymbol{t} \text { tests } \\
\mathbf{P}\end{array}$ & $\boldsymbol{d}$ \\
\hline Hypersensitivity & 0 & 3.57 & $0.59(0.61)$ & $0.68(0.66)$ & $0.50(0.53)$ & -4.872 & .000 & -0.30 \\
\hline Obsessive-compulsive & 0 & 4 & $1.10(0.70)$ & $1.15(0.71)$ & $1.03(0.68)$ & -2.549 & .011 & -0.17 \\
\hline Anxiety & 0 & 3.56 & $0.49(0.56)$ & $0.60(0.63)$ & $0.37(0.45)$ & -6.586 & .000 & -0.42 \\
\hline Hostility & 0 & 4 & $0.67(0.66)$ & $0.69(0.68)$ & $0.64(0.64)$ & -1.127 & .260 & -0.07 \\
\hline Somatization & 0 & 3.75 & $0.64(0.59)$ & $0.73(0.67)$ & $0.53(0.47)$ & -5.320 & .000 & -0.34 \\
\hline Depression & 0 & 3.90 & $0.67(0.58)$ & $0.79(0.64)$ & $0.55(0.50)$ & -6.503 & .000 & -.041 \\
\hline Sleep disturbance & 0 & 4 & $0.97(1.05)$ & $1.03(1.11)$ & $0.89(0.98)$ & -2.174 & .030 & -0.13 \\
\hline
\end{tabular}

$\mathrm{SD}$, standard deviation. 
and age, as expected and in line with previous studies (Abuín \& de Rivera, 2014; Casullo \& Castro Solano, 1999; Carrasco Ortíz et al., 2003; González de Rivera et al., 1999), negative and low associations were found between age and hypersensitivity and hostility; and no associations were found with anxiety, somatization or depression. Additionally, a negative and low association with the obsessive-compulsive scale, and a positive and low association with Sleep disturbance were found. However, all of these relationships are extremely low, and thus results should be cautiously considered.

Lastly, when comparing scales to assess which symptoms were more recurrent, a within-subjects ANOVA indicated that: obsessive-compulsive was the most frequent type of symptoms, followed by Sleep disturbance, then depression and hostility - with no differences between them next, Somatization and Hypersensitivity; and finally, anxiety. This finding partially reproduces previous results where anxiety and mood disorders are concluded to be the most prevalent (Akihiro et al., 2015; Aillon et al., 2014; Caparrós Caparrós et al., 2007; Casullo, 2004; Chadda, 2015; González de Rivera et al., 1999; Kessler et al., 2005; Klimas, Neary, McNicholas, Meagher, \& Cullen, 2014; Patel \& Stein, 2015; Sánchez \& Ledesma, 2009; The ESEMeD/MHEDEA 2000 Investigators et al., 2004; Stylianidis, Pantelidou, Chondros, Roelandt, \& Barbato, 2014). As expected, Obsessive-Compulsive and Depression were among the most frequent ailments, however, Anxiety symptoms turned out to be the least frequent. This latter result was unexpected since previous research clearly states that anxiety disorders are fairly common. A probable cause may rely on the Anxiety scale content, since seven out of nine items mostly refer to fear rather than to concerns. For examples, statements are I fear being alone, I feel afraid and I am afraid when I am in the street or in open spaces. Thus, although fear is one of the main features of anxiety disorders, these items may not accurately represent the hypervigilance, agitation, nervousness, and tension aspects, which are certainly central in background research where anxiety symptoms arose as one of the main mental disor-

Table 5. Pearson's $r$ correlations between age and the main clinical scales.

\begin{tabular}{lcc}
\hline & \multicolumn{2}{c}{ Pearson's correlations } \\
\hline Hypersensitivity & $\boldsymbol{r}$ & $\mathbf{P}$ \\
\hline Obsessive-compulsive & -.09 & .004 \\
\hline Anxiety & -.07 & .019 \\
\hline Hostility & -.03 & .350 \\
\hline Somatization & -.13 & $<.001$ \\
\hline Depression & .05 & .127 \\
\hline Sleep disturbance & .02 & .636 \\
\hline
\end{tabular}

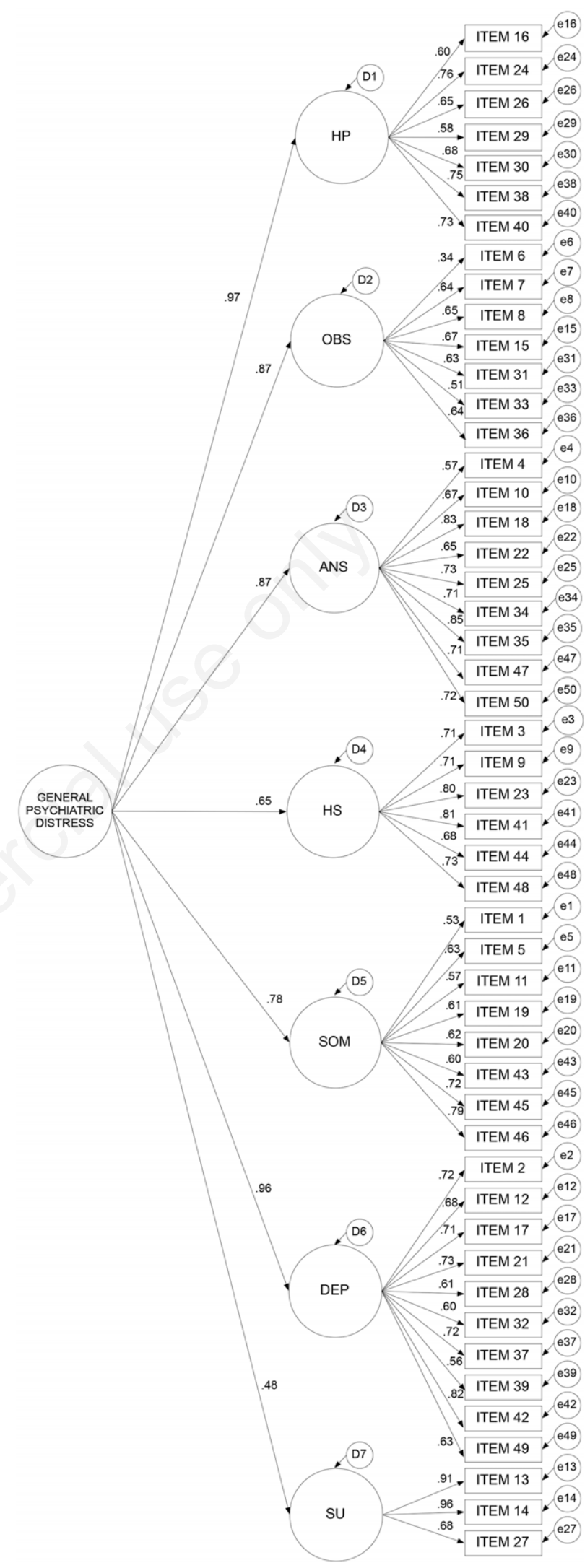

Figure 1. Second-order confirmatory factor analysis. HP, hypersensitivity; OBS, obsessive-compulsive; ANS, anxiety; HS, hostility; SOM, somatization; DEP, depression; SU, sleep disturbance. 
ders. Also, it is interesting that Sleep disturbance had such a relevant place being the second most informed set of symptoms. This endorses de Rivera and Abuín's (2012) decision of including such an important aspect in a psychopathology screening measure.

\section{Conclusions}

In conclusion, appropriate psychometric properties were found for the LSB-50 among adult population in Argentina. Results indicate that the use of scales scores as well as a total score is justified. Reliability of the scores was satisfactory. This evidence complements and increases the study of the LSB-50 worldwide. In comparison to previous studies (Abuín \& de Rivera, 2014; de Rivera \& Abuín, 2012; Rojas Gualdrón, 2012) where difficulties were found in validating the factorial structure proposed, this research backs up the structure of a second order factor structure with a total score as well as partial scores for each set of symptoms. This instrument will enable Argentinean researchers, therapists and other mental health professionals to rapidly and easily assess psychopathology. Whether the purpose is to research, to refer to treatment or to monitor treatment progress, the LSB50 will be a useful tool.

Regarding the limitations of the study, the use of a nonprobabilistic sample could have affected the results obtained. Therefore, a cross-validation and factorial invariances tests with bootstrap procedures are recommended for future studies. Additionally, although the LSB50 provides users a method to assess possible distortions in responses, that data was not weighted in the analyses of the present study since this was not the main focus of the analysis proposed here, and as pointed out by Chan (2009) the role of distorted answers in self-report measures is overestimated. However, further studies should explore this aspect.

In terms of psychometric properties, the study of possible convergence with independent measures is needed. Moreover, reliability aspects could be more accurately analysed using ordinal alphas (Elosúa \& Zumbo, 2008). Furthermore, information about specificity, sensitivity, positive and negative predictive values as well as receiving operating characteristic curves to determine adequate cut-off values would be important especially for clinician use. All these aspects would allow having a reliable, valid and brief screening instrument for assessing psychopathology in Argentinean adults.

\section{References}

Abuín, M.R., \& de Rivera, L. (2014). La medición de síntomas psicológicos y psicosomáticos: El Listado de Síntomas Breve (LSB-50) [The assessment of psychological and psychosomatic symptoms: The Short Checklist of Symptoms (LSB50)]. Clínica y Salud, 25, 131-141. doi: 10.1016/j.clysa. 2014.06.001
Akihiro, N., Mayumi, Y., Hirofumi, U., Takahiro, W., Kenshin, M., Osamu, T., Ryosuke, U., \& Toshiki, S. (2015). Prevalence of mental illness, intellectual disability, and developmental disability among homeless people in Nagoya, Japan: A case series study. Psychiatry and Clinical Neurosciences, 69(9), 534-542. doi: 10.1111/pen. 12265

Aillon, J.L., Ndetei, D.M., Khasakhala, L., Ngari, W.N., Achola, H.O., Akinyi, S., Ribero, S. (2014). Prevalence, types and comorbidity of mental disorders in a Kenyan primary health centre. Psychiatry and Psychiatric Epidemiology, 49(8), 1257-1268. doi: 10.1007/s00127-013-0755-2

Aoian, K.J., Patsdaughter, C.A., Levin, A., \& Gianan, M.E. (1995). Use of the Brief Symptom Inventory to assess psychological distress in three immigrants groups. International Journal of Social Psychology, 41(1), 31-46.

Bados, A., Balaguer, G., \& Coronas, M. (2005). ¿Qué mide realmente el SCL 90 R?: Estructura factorial en una muestra mixta de universitarios y pacientes [What does the SCL-90$\mathrm{R}$ really measure? Factorial structure in a mixed sample of undergraduates students and patients]. Psicología Conductual Revista Internacional de Psicología Clínica de la Salud, 13(2), 181-196.

Benishek, L.A., Hayes, C.M., Bieschke, K.J., \& Stoffelmayr, B.E. (1998). Exploratory and confirmatory analyses of the Brief Symptom Inventory among substance abusers. Journal of Substance Abuse, 10(2), 103-114.

Bonynge, E.R. (1993). Unidimensionality of SCL-90-R scales in adult and adolescent crisis samples. Journal of Clinical Psychology, 49(2), 212-215. doi: 0.1002/1097-4679(199303)49:2 $<212:$ :AID-JCLP2270490213>3.0.CO;2-V

Boulet, J., \& Boss, M.W. (1991). Reliability and validity of the Brief Symptom Inventory. Psychological Assessment, 3, 433437. doi: 10.1037/1040-3590.3.3.433

Canetti, L., Shalev, A.Y., \& De-Nour, A.K. (1994). Israeli adolescents' norms of the Brief Symptom Inventory (BSI). Israel Journal of Psychiatry and Related Sciences, 31(1), 1994, 13-18

Caparrós Caparrós, B., Villar Hoz, E., Juan Ferrer, J., \& Viñas Poch, F. (2007). Symptom Check-List-90-R: Fiabilidad, datos normativos y estructura factorial en estudiantes universitarios [Symptom Check-List-90-R: Reliability, normative data and factorial structure in college students]. International Journal of Clinical and Health Psychology, 7(3), 781-794.

Carrasco Ortiz, M.A., Sánchez Moral, V., Ciccotelli, H., \& del Barrio, V. (2003). Listado De Síntomas SCL-90-R: Análisis de su Comportamiento en una Muestra Clínica [Symptom Check List SCL-90-Revised: Analysis In Psychiatric Patients]. Acción Psicológica, 2(2), 149-161.

Casullo, M.M. (1983). Prevalencia de síntomas psiquiátricos en la ciudad de Buenos Aires y conurbano [Prevalence of psychiatric symptoms in Buenos Aires City and its Great Metropolitan Area]. Documenta Laboris, 4. Programa de Investigaciones sobre Epidemiología Psiquiátrica, CONICET.

Casullo, M.M. (1998). El Listado de Síntomas SCL-90-R de Derogatis [The Derogatis' Symptom Check List SCL-90-R]. Buenos Aires: Facultad de Psicología, Universidad de Buenos Aires.

Casullo, M.M. (2004). Síntomas psicopatológicos en adultos urbanos [Psychopathological symptoms in urban adults]. Psicología y Ciencia Social, 6(1), 49-57.

Casullo, M.M., \& Castro Solano, A. (1999). Síntomas psicopatológicos en estudiantes adolescentes argentinos. Aportaciones del SCL-90 [Psychopatological symptoms in 
Argentinean adolescent students. Contributions of the SCL90]. Anuario de Investigaciones, 7, 147-157.

Casullo, M.M., Cruz, M., González, R., \& Maganto, C. (2003). Síntomas psicopatológicos en adolescentes: Estudio comparativo [Psychopatological symptoms in adolescents: A comparative study]. Revista Iberoamericana de Diagnóstico y Evaluación Psicológica, 16(2), 131-151.

Cwikel, J., Zilber, N., Feinson, M., \& Lerner, Y. (2008). Prevalence and risk factors of threshold and sub-threshold psychiatric disorders in primary care. Social Psychiatry and Psychiatric Epidemiology, 43(3), 184-191. doi: 10.1007/ s00127-007-0286-9

Chadda, R.K. (2015). Common mental disorders in India. In S. Malhotra, \& S. Chakrabarti (Eds.) Developments in psychiatry in India (pp. 77-87). New Delhi: Springer India. doi: 10.1007/ 978-81-322-1674-2_6

Chapman, L.K., Petrie, J., \& Vines, L. (2012). Factor structure analysis of the SCL-90-R in a community-based sample of African American women. Psychiatry Research, 199(2), 140144. doi: 10.1016/j.psychres.2012.03.028

Chan, D. (2009). So why ask me? Are self-report data really that bad?. In C.E. Lance, \& R.J. Vandenberg (Eds.), Statistical and methodological myths and urban legends: Doctrine, verity and fable in the organizational and social sciences (pp. 309336). New York: Routledge/Taylor \& Francis Group.

Corcoran, K., \& Fischer, J. (2000). Measures for clinical practice. A sourcebook. New York: The Free Press.

Cyr, J.J., McKenna-Foley, J.M., \& Peacock, E. (1985). Factor structure of the SCL-90-R: Is there one?. Journal of Personality Assessment, 49(6), 571-578. doi: 10.1207/s15327752 jpa4906_2

Daoud, F.S., \& Abojedi, A.A. (2010). Equivalent factorial structure of the Brief Symptom Inventory (BSI) in clinical and nonclinical Jordanian populations. European Journal of Psychological Assessment, 26(2), 116-121. doi: 10.1027/ 10155759/a000016

De Las Cuevas, C., Gonzalez De Rivera, J.L., Henry Benitez, M., Monterrey, A.L., Rodriguez-Pulido, F., \& Gracia Marco, R. (1991). Análisis factorial de la versión española del SCL-90$\mathrm{R}$ en la población general [Factorial analysis of the Spanish version of the SCL-90-R in general population]. Anales de psiquiatría, 7(3), 93-96.

De Leo, D., Frisoni, G.B., Rozzini, R., \& Trabucchi, M. (1993). Italian community norms for the Brief Symptom Inventory in the elderly. British Journal of Clinical Psychology, 32, 209213. doi: 10.1111/j.2044-8260.1993.tb01045.x

Demyttenaere, K., Bruffaerts, R., Posada-Villa, J., Gasquet, I., Kovess, V., Lepine, J.P.,..., WHO World Mental Health Survey Consortium (2004). Prevalence, severity, and unmet need for treatment of mental disorders in the World Health Organization World Mental Health Surveys. Journal of the American Medical Association, 291(21), 2581-2590.

de Rivera, L., \& Abuín, M.L. (2012). LSB-50 Listado de Síntomas Breve: Manual [LSB-50 Short Checklist of Symptoms: Manual]. Madrid: TEA Ediciones.

Derogatis, L.R. (1975). Brief Symptom Inventory. Baltimore, MD: Clinical Psychometric Research.

Derogatis, L.R. (1983). SCL-90-R: Administration, scoring, and procedures manual II. Baltimore, MD: Clinical Psychometric Research.

Derogatis, L.R. (2001). The Brief Symptom Inventory 18 (BSI 18). Administration, scoring and procedures manual. Minneapolis, MN: NCS Pearson, Inc.
Derogatis, L.R., \& Spencer, M.S. (1982). The Brief Symptom Inventory (BSI): Administration, scoring, and procedures manual. Baltimore, MD: Johns Hopkins University School of Medicine, Clinical Psychometrics Research Unit.

Di Marco, G. (1981). Prevalencia de síntomas psiquiátricos en la ciudad de Buenos Aires y conurbano; variables sociológicos y síntomas psiquiátricos [Prevalence of psychiatric symptoms in Buenos Aires City and its Greater Metropolitan Area; sociological variables and psychiatric symptoms]. Documenta Laboris, 6. Programa de Investigaciones sobre Epidemiología Psiquiátrica, CONICET.

Eaton, W.W., Neufeld, K., Chen, L., \& Cai, G. (2000). A comparison of self-report and clinical diagnostic interviews for depression: Diagnostic interview schedule and schedules for clinical assessment in neuropsychiatry in the Baltimore epidemiologic catchment area follow-up. Archives of General Psychiatry, 57(3), 217-222. doi: 10.1001/archpsyc.57.3.217

Elosúa, P., \& Zumbo, B.D. (2008). Coeficientes de fiabilidad para escalas de respuesta categórica ordenada [Reliability coefficients for ordinal scales]. Psicothema, 20(4), 896-901.

Freiberg Hoffmann, A., Stover, J.B., de la Iglesia, G., \& Fernández Liporace, M. (2013). Correlaciones policóricas y tetracóricas en estudios exploratorios y confirmatorios. Ciencias Psicológicas, 7(2), 151-164.

Gempp Fuentealba, R., \& Avendaño Bravo, C. (2008). Datos normativos y propiedades psicométricas del SCL-90-R en estudiantes universitarios chilenos [Normative data and psychometric properties of the SCL-90-R in Chilean college students]. Terapia Psicológica, 26(1), 39-58.

Gennaro, A., Venuelo, C., Auletta, A.F., \& Salvatore, S. (2012). The topics of psychotherapy research: An analysis based on keywords. Research in Psychotherapy: Psychopathology, Process and Outcome, 15(1), 1-9. doi: 10.7411/RP.2012.001

Goldberg, D., \& Huxley, P. (1992). Common mental disorders: A biosocial model. London: Tavistock/Routledge.

González de Rivera, J.L., de las Cuevas, C., Gracia Marco, R., Henry Benítez, M., Rodríguez Pulido, F., \& Monterrey, A.L. (1999). Age, sex, and marital status differences in minor psychiatric morbidity. European Journal of Psychiatry, 5(3),166-176.

Grande, T.L. (2014). Path analysis of the SCL-90-R: Exploring use in outpatient assessment. Measurement and Evaluation in Counseling and Development, 47(4), 271-290. doi: 10.1177/ 0748175614538061

Hardt, J., Gerbershagen, H.U., \& Franke, P. (2000). The symptom checklist, SCL-90-R: Its use and characteristics in chronic pain patients. European Journal of Pain, 4(2), 137-148. doi: 10.1053/eujp.2000.0162

Hernández Aguado, I., Gilde Miguel, A., Delgado Rodriguez, M., Bolúmar Montrull, F., Benavides, F.G., ..., Lumbrera Lacarra, B. (2011). Manual de Epidemiología y Salud Pública para grados en Ciencias de la Salud [Handbook of Epidemiology and Public Health for undergraduates on Health Sciencies]. Madrid: Médica Panamericana.

Hoffmann, N.G., \& Overall, P.B. (1978). Factor Structure of the SCL-90 in a psychiatric population. Journal of Consulting and Clinical Psychology 46(6), 1187-1191. doi: 10.1037/ 0022-006X.46.6.1187

Holi, M. (2003). Assessment of psychiatric symptoms using the SCL-90 (Doctoral dissertation, Department of Psychiatry, University of Helsinki, Helsinki, Finland). Available from: http://ethesis.helsinki.fi/julkaisut/laa/kliin/vk/holi/assessme.pdf

Houghton, F., Keane, N., Murphy, N., Houghton, S., Dunne, C., 
Lewis, C.A., \& Breslin, M.J. (2012). The Brief Symptom Inventory-18 (BSI-18): Norms for an Irish third-level college sample. The Irish Journal of Psychology, 33(1), 43-62. doi: 10.1080/03033910.2012.672247

Kerlinger, F.N., \& Lee, H.B. (2000). Foundations of behavioral research. Orlando, FL: Harcourt Brace.

Kessler, R.C., Berglund, P., Demler, O., Jin, R., Merikangas, K.R., $\&$ Walters, E.E. (2005). Lifetime prevalence and age-of-onset distributions of DSM-IV disorders in the national comorbidity survey replication. Archives of General Psychiatry, 62, 593602. doi: 10.1001/archpsyc.62.6.593

King, M., Nazareth, I., Levy, G., Walker, C., Morris, R., Weich, S., ..., Torres-Gonzalez, F. (2008). Prevalence of common mental disorders in general practice attendees across Europe. British Journal of Psychiatry, 192(5), 362-367. doi: 10.1192/ bjp.bp.107.039966

Klimas, J., Neary, A., McNicholas, C., Meagher, D., \& Cullen, W. (2014). The prevalence of common mental and substance use disorders in general practice: A literature review and discussion paper. Mental Health and Substance Use, 7(4), 497508. doi: 10.1080/17523281.2014.939221

Kline, R.B. (2011). Principles and practice of structural equation modeling. New York: The Guilford Press.

Kohn, R., Levav, I., Caldas de Almeida, J.M., Vicente, B., Andrade, L., Caraveo-Anduaga, J.J., ..., Saraceno, B. (2005). Los trastornos mentales en América Latina y el Caribe: Asunto prioritario para la salud pública [Mental disorders in Latin American and the Caribbean: A priority in mental health]. Revista Panamericana de Salud Pública, 18(4/5), 229-240.

Lewis, G., Sheringham, J., Kalim, K., \& Crayford, T. (2008). Mastering public health: A postgraduate guide to examinations and revalidation: a guide to examinations and revalidation. London: Royal Society of Medicine Press.

Liu, Z., Chen, H., Cao, B., \& Jiao, F. (2013). Reliability and validity of Chinese version of Brief Symptom Inventory in high school students. Chinese Journal of Clinical Psychology, 21(1), 32-34

Loutsiou-Ladd, A., Panayiotou, G., \& Kokkinos, C.M. (2008). A review of the factorial structure of the Brief Symptom Inventory (BSI): Greek evidence. International Journal of Testing, 8(1), 90-110. doi:10.1080/15305050701808680

Martínez Azumendi, O., Fernández Gómez, C., \& Beitía Fernández, M. (2001). Variabilidad factorial del SCL-90-R en una muestra psiquiátrica ambulatoria [Factorial validity of the SCL-90-R in an outpatient psychiatric sample]. Actas ESpañolas de Psiquiatría, 29(2), 95-102.

Ministry of Health (2010). Estimación de la población afectada de 15 años y más por trastornos mentales y adicciones [Estimation of the population affected by mental disorders and addictions of 15 years or older]. Available from: http://www. inclusionmental.com.ar/contents/biblioteca/1329413814 -estimacion-de-la-poblacion-afectada-por-salud-mentalarg.pdf

Morlan, K.K., \& Tan, S. (1998). Comparison of the Brief Psychiatric Rating Scale and the Brief Symptom Report. Journal of Clinical Psychology, 54(7), 885-894. doi: 10.1002/(SICI) 1097-4679(199811)54:7<885::AID-JCLP3>3.0.CO;2-E

Muthen, B., \& Kaplan, D. (1985). A comparison of some methodologies for the factor analysis of non-normal Likert variables. British Journal of Mathematical and Statistical Psychology, 38, 171-189.

Noh, S., Avison, W.R., \& Kaspar, V. (1992). Depressive symptoms among Korean immigrants: Assessment of a translation of the center for epidemiologic studies-depression scale. Psychological Assessment, 4, 84-91. doi: 10.1037/1040-3590.4.1.84

Pagés Larraya, F., Casullo, M.M., \& Paso Viola, F. (1982). Prevalencia de la Patología Mental en la megalópolis de Buenos Aires [Prevalence of Mental Pathology in Buenos Aires megalopolis]. Documenta Laboris, 32. Programa de Investigaciones sobre Epidemiología Psiquiátrica, CONICET.

Patel, V. \& Stein, D.J. (2015). Common mental disorders in subSaharan Africa: The triad of depression, anxiety and somatization. In E. Akyeampong, A.G. Hill, \& A. Kleinman (Eds.). The culture of mental illness and psychiatric practice in Africa (pp. 50-72). Bloomington, IN: Indiana University Press.

Percevic, R., Lambert, M.J., \& Kordy, H. (2004). Computer-supported monitoring of patient treatment response. Journal of Clinical Psychology, 60(3), 285-299. doi: 10.1002/jclp.10264

Piersma, H.L., Boes, J.L., \& Reaume, W.M. (1994). Unidimensionality of the Brief Symptom Inventory (BSI) in adult and adolescent inpatients. Journal of Personality Assessment, 63(2), 338-344. doi: 10.1207/s15327752jpa6302_12

Polanczyk, G.V., Salum, G.A., Sugaya, L.S., Caye, A., \& Rohde, L.A. (2015). Annual research review: A meta-analysis of the worldwide prevalence of mental disorders in children and adolescents. Journal of Child Psychology and Psychiatry, $56(3), 345-365$.

Prinz, U., Nutzinger, D.O., Schulz, H., Petermann, F., Braukhaus, C., \& Andreas, S. (2013). Comparative psychometric analyses of the SCL-90-R and its short versions in patients with affective disorders. BMC Psychiatry, 13, 104. doi: 10.1186/1471244X-13-104

Prunas, A., Sarno, I., Preti, E., Madeddu, F., \& Perugini, M. (2012). Psychometric properties of the Italian version of the SCL-90R: A study on a large community sample. European Psychiatry, 27(8), 591-597. doi: 10.1016/j.eurpsy.2010.12.006

Rauter, U.K., Leonard, C.E., \& Swett, C.P. (1996). SCL-90-R factor structure in an acute, involuntary, adult psychiatric inpatient sample. Journal of Clinical Psychology, 52(6), 625-629. doi: $\quad 10.1002 /($ SICI)1097-4679(199611)52:6<625::AIDJCLP4>3.0.CO;2-J

Ritsner, M., Rabinowitz, J., \& Slyuzberg, M. (1995). The Talbieh Brief Distress Inventory: A brief instrument to measure psychological distress among immigrants. Comprehensive Psychiatry, 36, 448-453. doi: 10.1016/S0010-440X(95)90253-8

Rojas Gualdrón, D.F. (2012). Capacidad Explicativa de los Síntomas del LSB-50 sobre un Único Factor de Psicopatología General [Explained variance of a Single Factor of General Psycopathology by the LSB-50's symptoms]. Presented at the I Congreso Internacional de Psicología: Investigación y Responsabilidad Social, Bucaramanga, Colombia.

Ruipérez, M.A., Ibáñez, M.I., Lorente, E., Moro, M., \& Ortet, G. (2001). Psychometric properties of the spanish version of the BSI: Contributions to the relationship between personality and psychopathology. European Journal of Psychological Assessment, 17(3), 241-250. doi: 10.1027//1015-5759.17.3.241

Sahin, N.H., \& Durak, A. (1994). Kisa Semptom Envanteri (Brief Symptom Invetory-BSI): Turk Gencleri Icin Uyarlanmasi [A study of the Brief Symptom Inventory in Turkish Youth]. Turk Psikoloji Dergisi, 9(31), 44-56.

Sánchez, R.O., \& Ledesma, R.D. (2009). Análisis Psicométrico del Inventario de Síntomas Revisado (SCL-90-R) en población clínica [Psychometric Analysis of the Symptom Checklist Revised (SCL-90-R) in clinic population]. Revista Argentina de Clínica Psicológica, 18(3), 265-274.

Schmitz, N., Hartkamp, N., Kiuse, J., Franke, G.H., Reister, G., 
\& Tress, W. (2000). The Symptom Check-List-90-R (SCL90-R): A German validation study. Quality of Life Research: An International Journal of Quality of Life Aspects of Treatment, Care \& Rehabilitation, 9(2), 185-193. doi: 10.1023/A: 1008931926181

Shimokawa, K., Lambert, M.J., Smart, D.W. (2010). Enhancing treatment outcome of patients at risk of treatment failure: Meta-analytic and mega-analytic review of a psychotherapy quality assurance system. Journal of Consulting and Clinical Psychology, 78(3), 298-311. doi: 10.1037/a0019247

Sturm, K.A., Klebe, K.J., O'Keefe, M.L., Stucker, A.M., Livengood, M.L., \& Leggett, W.H. (2010). Comparing self-reports on the BSI with clinicians' reports on the BPRS. Presented at the Annual Meeting of the American Psychological Association, San Diego, CA, USA.

Stylianidis, S., Pantelidou, S., Chondros, P., Roelandt, J.L., \& Barbato, A. (2014). Prevalence of mental disorders in a Greek island. Psychiatriki, 25(1), 19-26.

The ESEMeD/MHEDEA 2000 Investigators, Alonso, J., Angermeyer, M.C., Bernert, S., Bruffaerts, R., Brugha, T.S., ..., Vollebergh, W.A.M. (2004). Prevalence of mental disorders in Europe: results from the European Study of the Epidemiology of Mental Disorders (ESEMeD) project. Acta Psychiatrica Scandinavica, 109, 21-27. doi: 10.1111/j.1600-0047. 2004.00327.x

Torres, L., Miller, M.J., \& Moore, K.M. (2013). Factorial invariance of the Brief Symptom Inventory-18 (BSI-18) for adults of Mexican descent across nativity status, language format, and gender. Psychological Assessment, 25(1), 300-305. doi: 10.1037/a0030436

Urbán, R., Kun, B., Farkas, J., Paksi, B., Kökönyei, G., Unoka, Z., ..., Demetrovics, Z. (2014). Bifactor structural model of symptom checklists: SCL-90-R and Brief Symptom Inventory (BSI) in a non-clinical community sample. Psychiatry Research, 216(1), 146-154. doi: 10.1016/j.psychres.2014.01.027

Vassend, O., \& Skrondal, A. (1999). The problem of structural indeterminacy in multidimensional symptom report instruments. The case of SCL-90-R. Behaviour Research and Therapy, 37(7), 685-701. doi: 10.1016/S0005-7967(98) 00182-X

WHO International Consortium in Psychiatric Epidemiology (2000). Cross-national comparisons of the prevalences and correlates of mental disorders. Bulletin of the World Health Organization, 78(4), 413-426.

WHO (2015). Gender and women's mental health. Gender disparities and mental health: The facts. Available from: http://www.who.int/mental_health/prevention/genderwomen/en/

Zack, M., Toneatto, T., \& Streiner, D.L. (1998). The SCL-90 factor structure in comorbid substance abusers. Journal of Substance Abuse, 10(1), 85-101. doi: 10.1016/S0899-3289(99) 80143-6

Zhang, J., \& Zhang, X. (2013). Chinese college students' SCL90 scores and their relations to the college performance. Asian Journal of Psychiatry, 6(2), 134-140. doi: 10.1016/j.ajp.2012. 09.009 